\title{
What is the future of ethics teaching in the environmental sciences
}

\author{
José Roque Junges ${ }^{1,2,3}$
}

Published online: 11 February 2016

C The Author(s) 2016. This article is published with open access at Springerlink.com

\begin{abstract}
The article begins with the interaction between scientific knowledge, environmentalism and society, demonstrating how, at the beginning of the environmental movement, the scientific arguments of ecological science served as ethical justification for reporting the causes of environmental degradation. Subsequently, the environmental sciences encompassed the knowledge of human, social, political and economic ecology in which the central question is not the pure denunciation, but the proposals of solutions to the environmental crisis. The environmental knowledge of human and social sciences lead to greater ethical implications because they underlie moral positions. Thus, a question arises: what is a suitable model of ethics for the environmental sciences? There are three models: weak anthropocentrism, mitigated biocentrism, and global biocentrism or ecocentrism. The last seems more consistent with ecology, because it puts the ethical emphasis on the preservation of interdependent sets of living beings. Bearing in mind the environmental science and the resulting model of ethics, what are the objectives of the teaching of ethics in the context of environmental science? Such teaching needs to include emotional and cognitive oriented goals because they are related both to the learning of skills to analyse different situations and to the awakening of ethical sensitivity to critically reflect upon them.
\end{abstract}

Keywords Ecology $\cdot$ Environmental sciences · Environmentalism · Ethics teaching · Ecocentrism $\cdot$ Environmental justice

The environmental crisis is already a proven fact that worries society because of its negative consequences in the short and long term for which solutions that can mitigate

José Roque Junges

roquejunges@hotmail.com

1 Graduate Program in Public Health, UNISINOS, São Leopoldo, RS, Brazil

2 Graduate Program in Bioethics, University of Brasilia (UnB), Brasília, DF, Brazil

3 P.O. box 101, 93001-970 São Leopoldo, RS, Brazil 
its effects and repair damage caused to the environment are being sought. In this setting, scientific and technological development is charting new paths for human and social progress in greater harmony with the rhythms of nature and respect for the surrounding environmental dynamics. However, techniques cannot be transformed into messianic solutions for environmental destruction since the crisis depends largely on human consumer behaviours which produce environmental damage and extract natural resources beyond the rate at which they may renew themselves. That is why we need an answer to the environmental crisis, not only the necessary scientific and technical solutions, but also changes in consumer habits of a utilitarian use of nature. It is necessary to rediscover the rhythms and dynamics of nature, as a wider and total environment, which involve artificial environments created by human ingenuity and determine their well-being. In other words, we must relearn how to understand nature as our common home. It means a change in attitude that has to do with ethics. Therefore, for the ecological issue, it is necessary to know how to combine environmental science with ethics and how to complement scientific expertise with ethical knowledge. Thus, the importance of teaching ethics in scientific ecology becomes essential.

\section{Science, society and environmentalism}

Since its inception, environmentalism, in its fight for the preservation of nature, has used scientific arguments to justify its denunciation of the exploitation and destruction of natural resources. Thus, ecological science was used to legitimize a social movement of an ethical slant (Castells 1997). Worster (1994) had already noticed such perspective long ago, when he pointed out that there were two streams in ecology science: a utilitarian approach which produced knowledge to better exploit natural resources and another, more holistic view, which promoted moral values of science, in which scientific knowledge was in the service of an ethical vision of nature - its interdependence. That is why Worster (1994) called the era that began in the 1960s the age of ecology. During that period a group of scientists, especially biologists, among whom were Rachel Carson (1962), Garrett Hardin (1968), Paul Ehrlich (1968), and Barry Commoner (1971), used scientific arguments to alert society to the risks of environmental degradation caused by population growth and technological progress for planet Earth. Thus, the scientific explanation of the cause of degradation ranged in emphasis between the growth of the population and the increasing use of technology. Discussions about environmental destruction culminated in Meadows' (1972) writings about the limits of population growth. These scientific contributions were important for the academic legitimacy of the environmentalism.

In that same time, a new kind of knowledge, called by Potter (1971) as Bioethics, emerged. It aimed at reflecting on the ethical challenges of the development and the proliferation of technologies that focused on the environment with negative effects on the reproduction of life. That is why Bioethics was presented as the science of survival of life on planet Earth, combining biological knowledge with ethical values in confronting the consequences of the binomial - technology and life. In this sense, environmental concerns and not clinical ones, which later happened with its development more focused on the medical perspective, were the origin of Bioethics. Over the 
years and by the criticism of Potter (1988), Bioethics was rediscovering its ecological origin, participating more in the discussion of environmental problems.

Later, environmentalism was no longer restricted to the halls of academia, but inserted itself in the social and political fights of society, demonstrating other concerns beyond pure denunciation of the causes of environmental degradation, proposing ways of solving the ecological crisis. In this new phase, environmentalism has gathered other knowledge, beyond that of ecology as biological science, encompassing contributions from human, social, political, and economic ecology. These contributions from human and social sciences have made the scientific explanation of the ecological issue more complex and have deepened its ethical vision, since it was not just its role to denounce the causes of environmental degradation, but also show the way and suggest solutions. With that in mind, the environmental crisis was not only a moral conflict in need of scientific explanations for its causes, but a challenge and an ethical imperative for society to build, with the contribution of science, alternative models for the management of natural resources and in living with nature.

Scientific knowledge of human ecology contributed to understanding the historical interactions between human societies and the natural environment for the constitution of different cultures (Hawley 1950). This understanding helped to question the vision of an untouched nature and the contrast between nature and society, typical of some more radical environmental movements. Nature always coexisted with the cultural management of its resources in integration between natural and cultural biodiversity. The problem, therefore, is not in the interaction between natural environment and human culture, but in the economic model which determined this interaction in recent centuries, causing damage and degradation to the environment.

The political ecology makes evident the social dimension of the environmental crisis by pointing out which groups suffer the most from the consequences of environmental degradation since there is not an equitable distribution of the damage. This phenomenon was termed "environmental injustice". The awareness of this injustice originated in a socio-environmental movement of denunciation and political struggle. It comes from the finding that, in societies characterized by social inequalities, negative externalities of economic processes are pushed into territories where socially fragile and discriminated populations who do not have the political strength to stop this disposal in their living space live. The beginning of that consciousness was in the black movement in the United States, which denounced the racism present in environmental degradation (Bullard 1996).

Another expression of political ecology that is no longer focused on race, but instead on gender, is ecofeminism (Warren 2000). For this movement, the problem of the environmental issue is not based on anthropocentrism, i.e., on the fact of being focused on the needs of human beings, but on the androcentrism, i.e., focus on man, in a male sense, who has always conducted the relations of domination in society through patriarchal models, which is also revealed in how nature considered a feminine entity - is treated. Ecofeminism underscores the character and the significance of correlations between the way women and nature are treated, pointing out the cultural correspondence between the domination of women and domination of nature.

A third political ecology movement, which emerged in the southern hemisphere, is the so-called "environmentalism of the poor" (Martínez-Alier 2010). This movement 
identifies itself with the political struggles of populations from underdeveloped countries, mainly indigenous peoples, peasants, and fishermen, who defend social and environmental sustainability of their traditional territories against the installation of large capitalist mining, oil, fishing, and agribusiness companies. In general, these fights are not seen as parts of environmental movements. These people fight against the environmental degradation that those companies cause when settling in their territory, defending the preservation of their ecosystem, the social reproduction of life. In this sense, these popular organisations, more than any other, have an environmental identity, because they fight for a non-instrumental utilitarian valorisation of nature, understood as our common home, our social-environmental ecosystem.

The struggles and accusations of political ecology point to the need for an ecological model of economy because the focus of the problem lies in the relationship between economic processes and environmental interdependencies of the nature. This is the core of Georgescu-Roegen's proposal (1971) of an ecological economy or bio-economy. It is based on the principles of general ecology transported, with due adaptations, to human ecology. It configures the economy based on physical flows of energy and materials, based on ecological balances and on a systemic view of the interrelationships between economy and nature, understanding it as a limit to economic processes and reducing the effects of entropy on productive processes. In this understanding, the economy is a subsystem of nature and not the other way around and economic processes are not mechanical ones, as in the classic view, but bio-based processes where there are entropic energy flows and externalities that cannot be disregarded, because they appear as effects in the environment.

The knowledge generated by the environmental sciences, from biological and human ecology to the social, political and economic one, point to the passage of the vision of nature as a set of natural resources to be transformed to respond to human needs, to an understanding of nature as a global ecosystem of environmental interdependencies that creates conditions necessary for the existence of life on the planet Earth. It moved from an instrumental utilitarian view of nature to a conception of its intrinsic value, independent of human needs.

In its beginning, the knowledge of biological ecology served as a scientific argument to legitimize environmentalism in its ethical complaint about the causes of environmental degradation. In recent times, the scientific knowledge generated by social, political and economic ecology needs ethics to justify its proposals for resolving the crisis. There is a difference, ethically speaking, between denouncing the causes and proposing solutions to the degradation of the environment. In the first, the scientific knowledge of ecology served as the ethical basis for environmentalism and, in the second, ethics became a requirement for the environmental sciences, where the point is to find answers to the problem. At that moment, the question arose: what is the ethical model for ecology?

\section{Trends of ecological ethics}

Classically, three trends in ecological ethics can be observed: weak anthropocentrism, mitigated biocentrism, global biocentrism or ecocentrism (Bartolommei 1995). The three of them come from the finding that there is an environmental crisis for which it is 
necessary to find a solution. The difference is in the focus of the response given to the problem.

The first focuses its solution on the human needs of ethical restructuring. In this sense it is anthropocentric because it is convinced that human beings need to change their behaviour in relation to nature, but it is still weak. Conservationists hold to the fact that natural resources are finite and, therefore, it is necessary to decrease the population and control consumption so that future generations can also have access to those material resources. Preservationists focus their ethical emphasis, not on the materiality of nature as the conservationists do, but in its aesthetic and symbolic sense that fills in and satisfies human spiritual needs. Learning and harmonic coexistence with nature give us knowledge and experiences that improve the moral comportment of human beings. In this sense nature needs to be preserved for its spiritual meaning.

The second trend argues that the environmental problem lies within human beings and in the satisfaction of their needs, and must focus on the needs of living beings. This is why it preaches overcoming speciesism, which claims that the human species is uniquely worthy of being a moral subject. If living beings feel pleasure and pain, it is not morally permissible to subject them to suffering (Singer 1976) and if they are subjects of life, by having a point of view about their lives, they are holders of rights (Regan 2004). Therefore, for biocentrism, animals are subjects and not just objects of morality. This is the great originality and contribution of the biocentric proposal.

The third trend, global biocentrism or ecocentrism, puts the emphasis on biotic communities. Unlikely biocentrism, with an individualizing vision of living beings, since each one is a moral subject in its individuality, ecocentrism puts the focus on preserving the interdependent environmental conditions of a biotic community. The origin of this trend is in "The Land Ethic" in Leopold (1970), whose ecological ethics takes as its starting point altruism in relation to all the living beings of a biotic community. As humans are bound to their fellows by feelings of empathy, called moral sentiments by Hume and Smith, it is possible to awaken those feelings in relation to the ecological community. For Leopold (1970) any ethical system is based on a single premise: the individual as a member of a community of interdependent parts. Ecology adds that it is necessary to extend the community to collectively include soil, water, plants, animals and the land. So, he called his ethics Land Ethic.

For Leopold (1970), an attitude is morally righteous when it tends to preserve the integrity, stability and beauty of the biotic community. It is wrong to do the opposite. His ethics is founded on the sense of belonging to a community, being, therefore a more holistic and ecocentred proposal than the previous ones. It derives environmental ethical values from facts known through ecology, evolutionary biology and human psychology. Starting from Hume, Leopold (1970) states that the knowledge of facts can produce two modes of conduct: discovery of the connection between cause and effect of those facts and the arousal of feelings of passion, respect and love about those facts.

Biology has led humanity to the knowledge that all forms of life, including the human, descended from common ancestors. Evolutionary biology showed the common kinship of all travellers in the adventure of life. The knowledge of this fact arouses love and respect, just as when you meet a relative. Ecological biology raises awareness of the existence of biotic communities to which everyone is connected as members. These links are no less close than those of human communities. Such knowledge awakens feelings of loyalty and membership, similar to those experienced in relation to social 
and national assemblies. The assumptions of "The Land Ethic" (Leopold 1970) are the knowledge that the earth is a biotic community, the subsequent awakening of feelings of love and respect for it, and from that, the emergence of a culture of the land.

"The Land Ethic" of Leopold inspired other models such as the Ecological Ethics of Rolston (1988) and the Bio-empathy of Callicott (1989). For the first, nature is a set of interrelationships in which each being is only one ring of a never-ending chain of matter, energy and information with the objective of preserving the web of life. Thus, to Rolston (1988) the ethical criterion is the stability of well-being interests of a biotic community. What matters is not so much the life itself, but the environment that allows the reproduction of life. In this sense, individual entities are subordinate to the wellbeing of the biotic community. So it is necessary to respect the laws inscribed in natural ecosystems and made explicit by ecology. It is the responsibility of human beings to take into account, in their ethics, these norms and adapt their behaviour to the homeostatic balance of the ecosphere. The Bio-empathy of Callicott (1989) argues that ethics is nothing more than a self-defence instinct of a community based on human feelings of sympathy. In this sense, ethics is an adaptive strategy to limit the freedom of action of human beings in the context of the fight for the survival of the human species. In that fight, the scope has thus far been restricted to areas of human coexistence, and it is therefore necessary to extend them to encompass the broader biotic community. It is about becoming aware of and awakening the responsibility of human beings in relation to their environment.

As the bodies of knowledge of the various environmental sciences (in their biological, human, social, political and economic aspects) headed toward a more holistic vision of nature as a set of socio-environmental interdependencies of the reproduction of life, the best-suited ethical model for this understanding is ecocentrism, because it defends the intrinsic value of nature as a web of biotic interrelationships in the service of the stability of life on planet Earth.

\section{The teaching of ethics in the context of environmental sciences}

The knowledge produced by the environmental sciences has ethical implications, because its goal is to get a reading of the environmental crisis and support proposals for a solution to its degrading effects on the environment. It is scientific knowledge which awakens to ethical challenges that can justify and drive to moral imperatives. In that sense, we cannot talk about an ethical neutrality of the environmental sciences, because the production of their scientific data can serve as justification and argumentation for the moral positions and initiatives of a social, political and economic nature in relation to the environment, hence, the importance and the role of the teaching of ethics in the environmental sciences. Here the fundamental question about how to teach ethics in this context appears.

Before anything else, it is necessary to start with the distinction between morals and ethics, affirming that this teaching must not be a moral indoctrination, but instead training for ethico-critical reflection. It is not about a way to enforce moral behaviour, but to create mental abilities, which are also attitudinal, for critically and ethically analysing situations in which ecological and environmental issues are involved. Thus this is an educational process based on the ethical autonomy and critical reflexivity of 
the moral subject. Bearing in mind the interactions between scientific knowledge and ethics in the context of environmental sciences, the teaching of training and competence in ethics cannot be reduced to a pure cognitive process of learning analytical skills, but must include ethical awareness and attitude through critical reflection on the situations, as they may require position-taking. A concrete example of such interaction between science and ethics is the scientific fight with ethical implications about the data that prove the global climate warming.

To discuss moral learning, this article takes for granted, as a starting point, the five objectives (goals) of the teaching of ethics proposed by Daniel Callahan (1980) by applying them to the field of learning in the environmental sciences: stimulating the moral imagination; recognizing ethical issues; developing analytical skills; eliciting a sense of moral obligation and personal responsibility; and tolerating and reducing disagreement and ambiguity.

The teaching of ethics cannot be an abstract activity, but must stimulate the imagination, arouse the feelings of the students for them to understand that there is a moral point of view because the contexts are configured by interdependencies which often require moral choices. Moral imagination helps to overcome the reduction of an ethical problem to a purely logical and cognitive analysis, but on the other hand, imagination without an analysis based on scientific knowledge becomes sterile (Callahan 1980). Moral imagination in the environmental sciences may be aroused by the critical contributions of the social and political ecology, developed by the ecofeminist movement and by the struggles of environmental justice and popular environmentalism. The knowledge and the discussion about the contributions of these movements may touch the emotional side of students in relation to the socialenvironmental effects of environmental degradation. But such emotional imagination needs to be corrected by the analyses of scientific ecology and ecological economy. This necessary interaction between moral imagination and scientific analysis points to an integrative learning between scientific knowledge and ethical knowledge.

Integration between moral imagination and scientific analysis is the basis of the objective proposed by Callahan (1980): the recognition of ethical issues. All the emotional awakening of morality leads to an assessment and judgement of cognitive nature in relation to the action which is expressed in the consciousness of ethical challenges faced by the moral subject. Emotions always engender an appreciation of the situation and by examining the rational validity of that assessment, ethical issues emerge. Leopold's Land Ethic and the Bio-empathy of Callicott may serve this purpose because they intend to create feelings of environmental interdependencies in relation to the biotic community, arousing the consciousness to the ethical issues involved. This awareness requires an examination of principles, rules and moral concepts involved in ethical issues, pointing to the role of rationality in their recognition. The proper perspective for this recognition is ecological rationality.

It is not enough to recognize an ethical issue, it is necessary to examine its routing and response pathways. According to Callahan (1980), this examination points to the following goal: developing analytical skills for the ethical issues roused by moral imagination. It is important to enable the student to be able to consistently and coherently analyse, through logical and practical skills in the application of principles, standards and concepts to justify moral judgements and argue in favour of ethical decisions. The ethical questions stirred by the environmental imagination need to pass 
through logical analysis and practice of the principles and concepts of ecological rationality assuming the perspective of environmental interdependencies of every being which inhabits a given ecosystem. This rationality, present in the proposal of Rolston's Ecological Ethics, may clarify whether certain action is an ecologically sustainable answer to the ethical question. Thus, the focus of the analysis is to reach the moral judgement and its practical decision is the social and environmental sustainability of a given human activity.

The ability of logical and practical analysis to make a decision concerning a particular ethical issue causes as a consequence, according to Callahan (1980), the following objective of the teaching of ethics: the sense of moral obligation. Ethics cannot be reduced to the logical implications of moral propositions: it must clarify the moral imperatives that follow ethical judgments. Actions are the result of moral judgements and manifest themselves as imperatives to act in accordance with the judgements. The sense of obligation is revealed in internal imperative demands to act according to what is perceived as a good and correct judgement - after the analysis of moral reasoning. The basis of moral responsibility is to assume, as an actor, the contents of action implemented and to answer for their consequences. This sense of responsibility is essential in relation to the effects of human actions on the environment. Certainly, the main scope of the teaching of ethics in the environmental sciences is to make different scientists of ecology promoters of ecological awareness in the society. Therefore, their scientific knowledge can awaken in citizens social and environmental responsibility in relation to the damage and degradation effects of social, economic and industrial activities on the sustainability of social and natural ecosystems.

Finally, as an ultimate goal of ethics teaching, Callahan (1980) proposes the reduction of ambiguities and tolerance regarding contrary opinions, because ethics requires the continuous examination of the premises of moral placement and permanent evaluation of the analyses and proposals of solutions to ethical issues. If any moral problem suffers from the complex interactions of the sociocultural context, changing its configuration and demonstration, ethical issues are even more affected in relation to the environment characterized by the ecological and social-environmental complexity of natural ecosystems which are traversed by human culture. This complexity demands a permanent analysis of ambiguities and a patient tolerance in the face of criticism and contrary positions to enhance the coherence of ethical discourses in the context of environmental sciences.

\section{Conclusion}

The environmental sciences have joined other ecological expertise beyond the biological ones, integrating scientific contributions of human, social, political and economic ecology, reaching a holistic view of nature understood as a common home and a set of social-environmental interdependencies of the reproduction of life. Ecocentric ethics stressed the intrinsic value of nature seen as a biotic community of living beings inhabiting certain ecosystems. The stability of vital conditions of such community becomes a moral reference. If the teaching of ethics has as its basis on an ecological vision of the environmental sciences and on an ecocentric and bioempathic environmental ethics model, its learning process needs to encompass both emotional and 
cognitive elements to foster ethical awareness regarding environmental issues, and to develop practices of ethical analysis, logic skills, and proposals for the construction of solutions.

Open Access This article is distributed under the terms of the Creative Commons Attribution 4.0 International License (http://creativecommons.org/licenses/by/4.0/), which permits unrestricted use, distribution, and reproduction in any medium, provided you give appropriate credit to the original author(s) and the source, provide a link to the Creative Commons license, and indicate if changes were made.

\section{References}

Bartolommei, S. 1995. Etica e Natura. Una "rivoluzione copernicana" in ética? Bari: Laterza.

Bullard, R. 1996. Unequal protection: Environmental justice and communities of color. San Francisco: Sierra Club Books.

Callahan, D. 1980. Goals in the teaching of ethics. In Ethics teaching in higher education, ed. D. Callahan and S. Bok, 61-80. New York / London: Plenum Press.

Callicott, J.B. 1989. In defense of the land ethic. Essays in environmental philosophy. New York: State of New York University Press.

Carson, R. 1962. Silent spring. Boston / New York: Houghton Mifflin Company.

Castells, M. 1997. The power of identity. In The information age: economy, society and culture, Vol. II. Cambridge, Oxford: Blackwell.

Commoner, B. 1971. The closing circle: Man and technology. Madison: Ed. Knopf.

Ehrlich, P.R. 1968. The population bomb. Rivercity: Rivercity Press.

Georgescu-Roegen, N. 1971. The entropy law and the economic process. Cambridge: Harvard University Press.

Hardin, G. 1968. The tragedy of the commons. Science 162: 1243-1248.

Hawley, A. 1950. Human ecology: A theory of community structure. New York: Ronald Press.

Leopold, A. 1970. A sand county almanac with essays on conservation from round river. New York: Ballantine Books.

Martínez-Alier, J. 2010. El Ecologismo de los pobres: Conflictos ambientales y lenguajes de valoración. Callao: Espiritrompa.

Meadows, D. 1972. The limits to growth. Cambridge: MIT.

Potter, V.R. 1971. Bioethics, bridge to the future. Englewood Cliffs: Prentice-Hall.

Potter, V.R. 1988. Global bioethics, building on the Leopold legacy. East Lansing: Michigan State University Press.

Regan, T. 2004. Empty gages: Facing the challenges of animal rights. Lanham: Rowman \& Littlefield Publishers.

Rolston, H. 1988. Environmental ethics: Duties to and values in nature. Philadelphia: Temple University Press.

Singer, P. 1976. Animal liberation: A new ethics for our treatment of animals. London: Jonathan Cape.

Warren, K.J. 2000. Ecofeminist philosophy. A western perspective on what it is and why it matters. Oxford: Rowman \& Littlefield Publishers.

Worster, D. 1994. Nature's economy: A history of ecological ideas, 4th ed. New York: Cambridge University. 